\title{
AVALIAÇÃO DO USO DE EFLUENTE DE CASAS DE FARINHA COMO FERTILIZANTE FOLIAR NA CULTURA DO MILHO (Zea mays L.)
}

\author{
Narcísio Cabral de Araújo ${ }^{1}$, Thiago Costa Ferreira², Suenildo Jósemo Costa Oliveira ${ }^{3}$, Carlos Pereira Gonçalves ${ }^{4}$, \\ Francisco de Assis Cabral de Araújo ${ }^{5}$
}

\section{RESUMO}

O milho (Zea mays L.) é um produto agrícola bastante cultivado no mundo, sendo que no Brasil é de grande importância para o agronegócio nacional, além de ser base de sustentação para a pequena propriedade. A aplicação de manipueira como fertilizante pode ser via foliar ou solo, sendo que a foliar é a mais viável, porque além de ser fonte suplementar de nutrientes pode servir como defensivo agrícola, ou seja, pode apresentar duplo efeito. A presente pesquisa objetivou analisar o uso da manipueira como fertilizante foliar na cultura do milho. O experimento foi conduzido em condições de campo, entre os meses de junho e agosto de 2010, no município de Lagoa Seca, PB. O delineamento experimental utilizado foi blocos causalizados, composto por cinco tratamentos, distribuídos em quatro blocos. Após 90 dias do plantio foram avaliadas as variáveis, altura da planta, altura de inserção da $1^{\mathrm{a}}$ espiga, diâmetro do caule, comprimento do caule, número de folhas e área foliar. Os resultados foram submetidos à análise de variância e da regressão polinomial, sendo utilizado o teste F para verificar a significância dos efeitos. Os resultados indicaram que, a aplicação da manipueira em suas diferentes dosagens proporcionou ganhos de fitomassa em todas variáveis estudadas, havendo diferença estatística $(\mathrm{p}<0,01)$ entre os tratamentos utilizados. A manipueira mostrou-se eficaz na adubação, via foliar, da cultura do milho, pois, todas as variáveis analisadas apresentaram valores superiores à testemunha absoluta.

Palavras-chave: Adubação foliar, injúria, manipueira.

\begin{abstract}
EVALUATION OF USE OF AFFLUENT FROM LEAF FLOUR MILLAS FERTILIZER IN CORN (Zea mays L.)

Corn (Zea mays L.) is grown throughout the world, and is an important crop for Brazilian agribusiness, and subsistence farmers. The application of fertilizer can be manipueira as foliar or soil, and the leaf is more feasible because besides being a source of additional nutrients may serve as a pesticide, or may have double effect. The present study aimed to analyze the use of cassava as a foliar fertilizer in corn. The experiment was done under field conditions between the months of June and August 2010 in the municipality of Lagoa Seca, Paraíba and was laid in randomized block design, with five treatments, and four replications. Plant height, insertion height of first spike, stem diameter and length, number of leaves and leaf area were determined 90 days after planting. The data were subjected to analysis of variance and polynomial regression, by using the $\mathrm{F}$ test to assess the significance. The application of different strengths of manipueira resulted in increased biomass in all variables $(p<0.01)$. The manipueira proved to be an efficient fertilizer, when applied to corn leaves.
\end{abstract}

Keywords: Foliar fertilization, injury, manipueira.

\section{Recebido para publicação em 01/09/2011. Aprovado em 01/08/2012.}

1- Eng. Sanitárista e Ambiental, Mestrando em Eng. Civil e Ambiental, Dept. de Eng. Civil, Universidade Federal de Campina Grande, narcisioaraujo@gmail.com

2- Graduando em Agroecologia, Dept. Ciências Agrária e Ambiental, Universidade Estadual da Paraíba, ferreira_uepb@hotmail.com

3- Eng. Agrônomo, Professor titular do Dept. de Ciências Agrária e Ambiental, Universidade Estadual da Paraíba, odlineus@oi.com

4- Eng. Agrônomo, Professor titular do Dept. de Ciências Agrária e Ambiental, Universidade Estadual da Paraíba, carlospereirauepb@gmail.com;

5- Graduando em Agronomia, Dept. Ciências Agrária, Universidade Federal da Paraíba, e-mail: leoeucop@hotmail.com

340 REVENG

340-349 p. ENGENHARIA NA AGRICULTURA, VIÇOSA - MG, V.20 N.4, JULHO / AGOSTO 2012 


\section{INTRODUÇÃO}

O Milho (Zea mays L.) vem sendo utilizado na América Latina desde os tempos mais remotos, como a principal e a mais tradicional fonte alimentar, ocupando hoje posição de destaque entre os cereais cultivados no mundo, precedido apenas pela cultura do trigo (BRITO et al., 2010). A cultura do milho no Brasil é de grande importância para o agronegócio nacional, além de ser base de sustentação para a pequena propriedade, devendo ser interpretada sob a ótica da cadeia produtiva ou dos sistemas agroindustriais, visto ser o milho insumo para diversos produtos (DUARTE et al., 2008 citado por OLIVEIRA et al., 2009). Em conformidade com dados do Instituto Brasileiro de Geografia e Estatística - IBGE (BRASIL, 2011), a produção brasileira de milho em grãos para a safra de 2010 foi de 33,3 milhões de toneladas em uma área cultivada de 12,89 milhões de hectares e a estimativa para a safra de 2011 é de 32,1 milhões de toneladas em uma área de 13,02 milhões de hectares.

$\mathrm{O}$ aproveitamento de efluentes na agricultura, seja este doméstico ou industrial, visa dar uma destinação final adequada aos resíduos gerados pelas atividades antrópicas, servindo de nutrientes para as culturas, aumentando sua produtividade.

Vários estudos têm sido realizados utilizando efluentes líquidos de casas de farinha como fertilizante: Aragão \& Ponte (1995), testaram o uso da manipueira como adubo foliar na cultura do quiabeiro (Hibiscus esculentus) e Borszowskei et al. (2009) no morangueiro (Fragaria x ananassa Duch.); Cardoso (2005) investigou o emprego de manipueira aplicada no solo como biofertilizante para cultivo do milho e Saraiva et al. (2007) avaliaram o desenvolvimento vegetativo do milho fertirrigado com o efluente.

A aplicação de biofertilizante líquido via foliar reduz, em grande parte, os problemas fitossanitários atuando no controle de várias pragas e moléstias, surgindo assim, como possível alternativa de nutrição e proteção para as culturas (COLLARD et al., 2001). A adubação orgânica via biofertilizantes representa alternativa promissora capaz de reduzir a aplicação de fertilizantes minerais no solo (ALVES et al., 2009). O mesmo acontece quando se faz adubação foliar, com manipueira, pois esta apresenta efeito tanto fertilizante como fitossanitário.

Segundo Cereda (2001), os problemas ambientais causados pela disposição inadequada de manipueira estão relacionados à sua composição química e ao grande volume de resíduo líquido gerado no processo de beneficiamento de raízes de mandioca, pois, por menores que sejam as unidades fabris, podem gerar quantidades significativas de resíduos, visto que geralmente costumam se instalar, em uma mesma comunidade ou município, grande número de casas de farinha.

A manipueira é um líquido de aspecto leitoso, cor amarelo-claro e que apresenta forte odor podendo causar sensações desagradáveis se o indivíduo a inalar por muito tempo, no momento de sua extração. O líquido é extraído na etapa do processamento de prensagem da massa oriunda das raízes de mandioca raladas para a produção de farinha e, ou, extração da fécula. Segundo Fioretto (2001), uma tonelada de raiz de mandioca gera, em média, 600 litros de manipueira, sendo que na operação de prensagem, durante os processos de fabricação de farinha, 20 a $30 \%$ desse líquido é eliminado. Em conformidade com o autor, o processamento de uma tonelada de raiz de mandioca corresponde a uma poluição equivalente à proporcionada por 200 - 300 habitantes por dia. Segundo Fioretto (2001), a manipueira, quando lançada em corpos d'água, apresenta dupla ação poluidora, em razão da elevada carga de DBO (30000 $\left.\mathrm{mg} \mathrm{L}^{-1}\right)$ e presença do íon cianeto associado a linamarina.

Takahashi (1987), Melo et al. (2006) e Borghetti (2009) apontam os efeitos adversos que esse efluente pode causar ao meio ambiente, se descartado de forma inadequada. As casas de farinha são fontes geradoras de produtos poluentes que podem afetar tanto a natureza como colocar em risco a saúde das pessoas que habitam suas proximidades, pois, estes lugares são propícios à proliferação de insetos, mosquitos e a exalação muito forte de odores fétidos.

A composição química da manipueira sustenta a potencialidade do composto como adubo, haja vista sua riqueza em potássio, nitrogênio, magnésio, fósforo, cálcio, e enxofre, além de 
ferro e micronutrientes em geral (PANTAROTO \& CEREDA, 2001). Portanto, pode-se depreender que a manipueira pode ser utilizada como fertilizante, de forma a se aproveitar e recircular os nutrientes no solo, evitando-se, assim, os despejos nos cursos d'água (FIORETTO, 2001).

$\mathrm{Na}$ presente pesquisa objetivou-se analisar o uso de diferentes diluições de manipueira, como fertilizante foliar, na cultura do milho (Zea mays $L$.).

\section{MATERIAL E MÉTODOS}

O experimento foi conduzido em condições de campo, entre os meses de junho e setembro de 2010, na Escola Agrícola Assis Chateaubriand, Campus II da Universidade Estadual da Paraíba; no município de Lagoa Seca, PB, mesorregião do Agreste da Paraíba, com as seguintes coordenadas geográficas: latitude $7^{\circ} 09^{\prime} \mathrm{S}$; longitude $35^{\circ} 52^{\prime} \mathrm{W}$. O clima da região é caracterizado como tropical úmido (As'), com temperatura média anual em torno de $22{ }^{\circ} \mathrm{C}$, sendo a mínima de $18{ }^{\circ} \mathrm{C}$ e a máxima de $33{ }^{\circ} \mathrm{C}$; altitude média de cerca de 634 $\mathrm{m}$ metros em relação ao nível do mar.

Segundo a Embrapa (1999), o solo da área experimental é classificado como Neossolo Regolítico, e cujas características químicas na profundidade de $0-20 \mathrm{~cm}$ estão apresentadas no Quadro 1.

O preparo do solo foi feito com gradagem, seguido, de abertura manual das covas e com auxílio de enxadas, onde foram semeadas quatro sementes por cova, da variedade de milho híbrido
BR 205. Durante todo o cultivo, realizaram-se capinas manuais com auxílio de enxada, para manter a cultura livre da competição proporcionada por outras plantas. A irrigação foi feita uma vez por semana com água do açude da referida escola agrícola, por sistema aspersão, utilizando-se um canhão hidráulico.

O fertilizante (manipueira), utilizado no experimento, foi coletado um mês antes de ser aplicado e foi armazenado em baldes de plástico hermeticamente fechados. Este material foi coletado em uma casa de farinha localizada no distrito de Jenipapo, município de Puxinanã, PB. Após a coleta e o armazenamento, realizou-se a caracterização físico-quimica de alguns parâmetros da manipueira, seguindo-se da metodologia proposta por APHA (1998) (Quadro 2).

$\mathrm{O}$ delineamento experimental utilizado foi em blocos casualizados, composto por cinco tratamentos, distribuídos em quatro blocos, totalizando 20 parcelas experimentais. Cada parcela experimental foi composta por quatro fileiras com $5 \mathrm{~m}$ de comprimento, utilizando-se o espaçamento de $1,00 \mathrm{~m}$ entre fileiras e $0,50 \mathrm{~m}$ entre covas. Quinze dias após a germinação foi feito o desbaste, deixando-se uma planta por cova, totalizando-se 40 plantas por parcela, o que corresponde a 160 plantas por tratamento. Para efeito de análise estatística, foram utilizadas apenas as duas fileiras centrais, de onde foram tomadas apenas 10 plantas, portanto, 40 plantas úteis por tratamento. A manipueira foi diluída em água do açude da referida escola agrícola, aplicado via foliar, com auxílio de um

Quadro 1. Características químicas do solo da área experimenta

\begin{tabular}{|c|c|c|c|c|c|c|c|c|}
\hline MO & pH & $\mathbf{P}$ & $\mathbf{N}$ & $\mathbf{K}$ & $\mathbf{A l}^{+3}$ & $\mathbf{C a}^{+2}$ & $\mathbf{M g}^{+2}$ & $\mathbf{N a}^{+}$ \\
\hline $\mathrm{g} \mathrm{dm}^{-3}$ & $\mathrm{H}_{2} \mathrm{O}$ & \multicolumn{7}{|c|}{$\mathrm{cmol} \mathrm{dm}^{-3}$} \\
\hline 14,1 & 6,13 & 0,87 & 0,8 & 33,0 & 0,0 & 39,2 & 22,3 & 0,7 \\
\hline
\end{tabular}

Quadro 2. Caracterização média da manipueira utilizada no experimento.

\begin{tabular}{|c|c|c|c|c|c|c|c|c|c|}
\hline pH & $\mathbf{C E}$ & At & AGV & DQO & SST & SSV & SSF & NTK & $\mathbf{P t}$ \\
\hline - & $\mathrm{mS} \mathrm{cm} \mathrm{cm}^{-1}$ & $\mathrm{mg} \mathrm{L}^{-1} \mathrm{CaCO}_{3}$ & & & & $\mathrm{~g} \mathrm{~L}^{-1}$ & & & \\
\hline 4,5 & 8,43 & $1.623,6$ & 11,70 & 141,03 & 65,63 & 51,37 & 14,26 & 2,05 & 0,273 \\
\hline
\end{tabular}

Legenda: At: Alcalinidade total; AGV: Ácidos Graxos Voláteis; DQO: Demanda Química de Oxigênio; SST: Sólidos Suspensos Totais; SSV: Sólidos Suspensos Voláteis; SSF: Sólidos Suspensos Fixos; NTK: Nitrogênio Total Kjeldahl; Pt: Fósforo Total. 
pulverizador manual, em intervalos de tempo de 15 dias para cada tratamento, os quais tiveram início 5 dias após o desbaste, totalizando-se 4 aplicações durante todo o ciclo vegetativo do milho.

Os tratamentos foram caracterizados por: $0 \%$ de manipueira $+100 \%$ de água; $25 \%$ de manipueira + $75 \%$ de água; $50 \%$ de manipueira $+50 \%$ de água; $75 \%$ de manipueira $+25 \%$ de água; e $100 \%$ de manipueira $+0 \%$ de água.

A calda pulverizante foi aplicada uma vez nas duas faces das folhas, segundo metodologia proposta por Camargo \& Silva (1985). Nas duas primeiras aplicações, cada fileira foi pulverizada com $400 \mathrm{~mL}$ da calda (manipueira + água), e nas duas últimas aplicações o volume foi aumentado para $600 \mathrm{~mL}$ - isto em decorrência do aumento da área foliar das plantas, o que necessitou de um volume maior para garantir que todas as folhas ficassem bem pulverizadas - que corresponde a 40 e $60 \mathrm{~mL}$, respectivamente, da diluição por planta.

Após 90 dias do plantio, foram mensuradas as características de crescimento do milho, avaliandose as seguintes variáveis: Altura de Planta (AP), tomada com uma trena graduada em centímetro, na superfície do solo a extremidade da panícula; Altura de Inserção da Espiga (AIE), tomada com uma trena graduada em centímetro, da superfície do solo até a inserção da espiga inferior; Diâmetro de Caule (DC), tomado com paquímetro graduado em centímetros, no primeiro entre nó da planta; Comprimento de Caule (CC), tomada com uma trena graduada em centímetro, da superfície do solo até a inserção inferior da panícula; Número de Folhas (NF), contando todas as folhas verdes existentes na planta. Para a variável área foliar (AF), foram medidas o comprimento (L) e largura (B) de todas as folhas por meio do método proposto por Francis et al. (1969). Oito dias após a quarta aplicação do biofertilizante, avaliou-se o percentual de folhas com injúria, referente a cada tratamento.

Os resultados das características de crescimento do milho foram submetidos à análise de variância através do software ASSISTAT v. 7.6 Beta, e interpretados estatisticamente por meio da análise de variância e regressão polinomial, sendo utilizado o teste F para verificar a significância dos efeitos.

\section{RESULTADOS E DISCUSSÃO}

A utilização das diferentes dosagens de manipueira nas concentrações de $0 \%, 25 \%, 50 \%$, $75 \%$ e $100 \%$ influenciaram de forma significativa as variáveis: altura da planta, altura de inserção da $1^{\text {a }}$ espiga, comprimento do caule, diâmetro do caule, número de folhas e área foliar, referentes à cultura do milho, híbrido BR 205, aos 90 dias após o plantio.

Observando-se os resultados apresentados no Quadro 3, percebe-se que a aplicação da manipueira em suas diferentes dosagens proporcionou ganhos de fitomassa nas três variáveis estudadas, havendo diferença estatística $(p<0,01)$ entre os tratamentos utilizados.

Quadro 3. Resumo da análise de variância (Quadrado médio) das variáveis, altura de planta (AP), comprimento de caule (CC) e diâmetro de caule (DC), em função das concentrações $0 \%, 25 \%$, $50 \%, 75 \%$ e $100 \%$ de manipueira aplicada via foliar na cultura do milho.

\begin{tabular}{lcccc} 
& & \multicolumn{3}{c}{ Quadrado Médio } \\
\cline { 3 - 5 } \multicolumn{1}{c}{ FV } & GL & AP & CC & DC \\
\hline Regressão Linear & 1 & $1.316,75625^{* *}$ & $1.177,22500^{* *}$ & $0,00006^{\text {ns }}$ \\
Regressão Quadrática & 1 & $868,21875^{* *}$ & $325,44643^{* *}$ & $0,16612^{* *}$ \\
Desvio da Regressão & 2 & $15,79375^{\text {ns }}$ & $12,22232^{\text {ns }}$ & $0,01157^{\text {ns }}$ \\
Tratamento & 4 & $550,64375^{* *}$ & $392,23750^{* *}$ & $0,04669^{* *}$ \\
Bloco & 3 & $939,04583^{* *}$ & $924,90000^{* *}$ & $0,09313^{* *}$ \\
Resíduo & 12 & 40,28542 & 33,087 & 0,00302 \\
CV\% & - & 2,66768 & 2,94530 & 2,17456 \\
\hline$* * * e^{\text {ns }}$ & Significtivo a 1 a $5 \%$ de probabilade não significativo, respectivamente (Teste F)
\end{tabular}

**, * e ns - Significativo a 1 e a $5 \%$ de probabilidade e não significativo, respectivamente (Teste $\mathrm{F}$ ).

Legenda: FV: Fonte de Variação; CV: Coeficiente de variação; GL: Grau de liberdade. 
Para a variável altura de planta, pode-se constatar que o efeito na curva de crescimento apresentou tendência quadrática $(\mathrm{p}<0,01)$, ou seja, houve uma maior altura de plantas até a dosagem de $75 \%$, havendo em seguida uma diminuição no crescimento, quando se utilizou a dosagem acima deste percentual (Figura 1). Uma provável explicação para esse decréscimo pode ser uma redução da atividade fotossintética, decorrente da intoxicação provocada nas folhas da plante quando se aplicou manipueira pura (pulverização do milho com manipueira a $100 \%$ ).

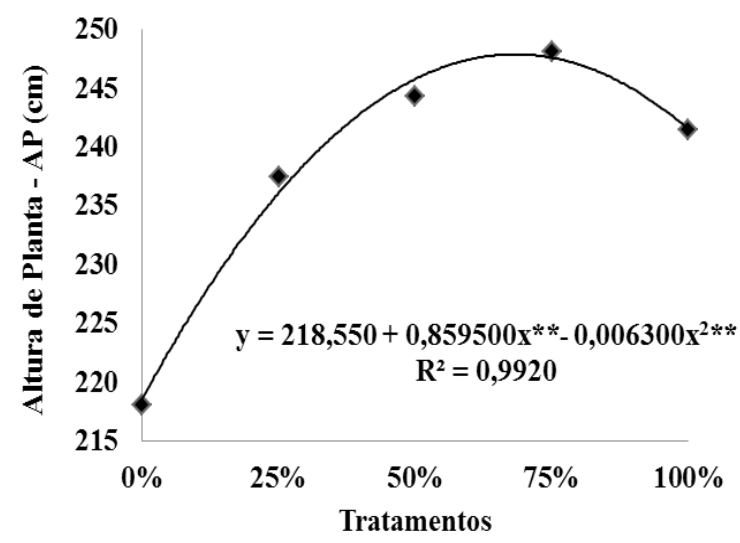

Figura 1. Regressão dos valores médios da altura de planta $(\mathrm{AP}, \mathrm{cm})$ do milho em função dos tratamentos.

O efeito da análise de regressão foi quadrático ( $\mathrm{p}$ $<0,01)$ significativo, para a variável comprimento de caule das plantas (Figura 2), com comprimento máxima de 204,62 cm, também para o tratamento com aplicação de $75 \%$ de manipueira, o que representa aumento de 13,04\% em relação ao tratamento com aplicação de $0 \%$ de manipueira.

Castro \& Prezotto (2008) avaliaram o desenvolvimento da cultura do milho após utilização de diferentes adubos orgânicos, propiciada pela utilização de adubos verdes, sendo constituído o ensaio por quatro tipos diferentes de leguminosas e um tratamento testemunha; havendo diferenças significativas para a variável altura total entre os tratamentos.

A variável diâmetro de caule apresentou os seguintes resultados médios, em centímetros, de 2,$43 ; 2,52 ; 2,67 ; 2,58$ e 2,41 ; para as dosagens 0 ; $25 ; 50 ; 75$ e $100 \%$ de manipueira, respectivamente. $\mathrm{Na}$ Figura 3, está representada sua análise de regressão polinomial, a qual apresentou efeito quadrático $(\mathrm{p}<0,01)$ significativo, sendo que o diâmetro máximo obtido foi de $2,67 \mathrm{~cm}$ com aplicação de manipueira na concentração de 50\%, ou seja, aumento percentual de $9,87 \%$ quando comparado com a testemunha.

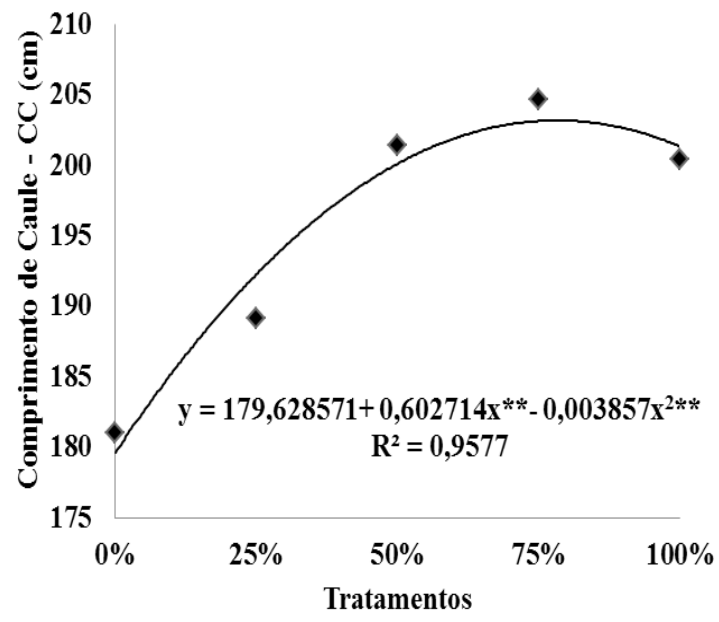

Figura 2. Regressão dos valores médios do comprimento de caule $(\mathrm{CC}, \mathrm{cm})$ do milho em função dos tratamentos.

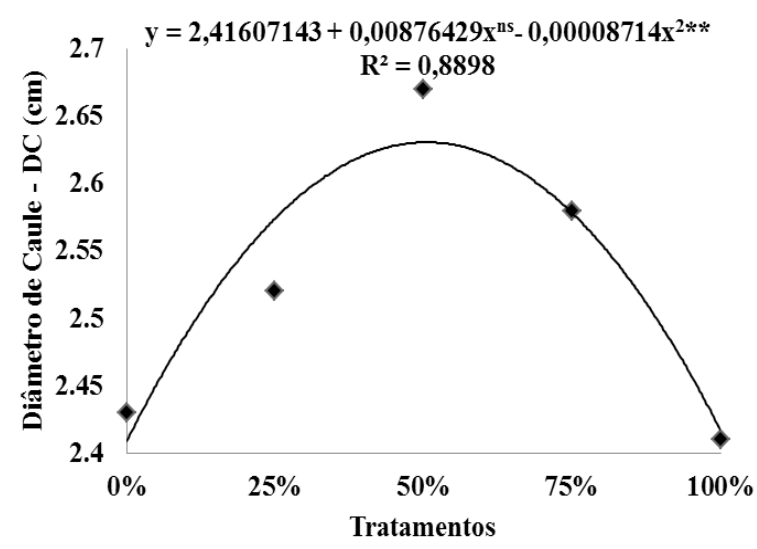

Figura 3. Regressão dos valores médios do diâmetro de caule (DC, $\mathrm{cm})$ do milho em função dos tratamentos.

Utilizando-se manipueira de tanque de decantação e lagoas de estabilização anaeróbias, Saraiva et al. (2007) realizaram um estudo na qual consistia na aplicações do efluente nas concentrações 50 e $100 \%$, diluida em água destilada e aplicada no solo, com a cultura do milho, na qual pode ser constatado que o diâmetro caulinar apresentou diferença significativa quando comparada com a testemunha.

\section{REVENG 340-349 p.}


Castro \& Prezotto (2008) avaliaram o desenvolvimento da cultura do milho, após utilização de diferentes adubos orgânicos, propiciada pela utilização de adubos verdes, sendo constituído o ensaio por quatro tipos diferentes de leguminosas e um tratamento testemunha; havendo diferenças significativas para a variável, diâmetro do colmo entre os tratamentos.

Observando-se os dados apresentados no Quadro 4, percebe-se que a aplicação da manipueira, em suas diferentes dosagens, proporcionou ganhos de fitomassa nas três variáveis estudadas, havendo diferença significativa $(\mathrm{p}<0,01)$ entre os tratamentos utilizados. Para altura de inserção da $1^{\text {a }}$ espiga (Figura 4), a análise de regressão apresentou efeito quadrático $(\mathrm{p}<0,01)$ significativo, sendo $102,87 \mathrm{~cm}$ o máximo valor obtido, para o tratamento com aplicação de $75 \%$ de manipueira. Esse crescimento representa aumento de 26,60\% em relação à testemunha.

Siqueira et al. (2009) avaliaram a ação de dois fertilizantes orgânicos (Bacsol e Orgasol) no cultivo de milho, na altura de inserção da $1^{\mathrm{a}}$ espiga e coloração dos grãos na cultura do milho orgânico e constataram diferenças significativas entre os tratamentos, sendo superior, na altura da inserção da espiga, o tratamento que não recebeu a aplicação dos produtos. Por outro lado, objetivando verificar o desempenho da cultura do milho sob plantio direto, com e sem a aplicação de $\mathrm{N}$ em cobertura, em sucessão a adubos verdes de verão, Santos et al. (2010) concluíram que a adubação verde influenciou positivamente a altura de inserção da $1^{a}$ espiga do milho, mesmo na ausência da adubação nitrogenada mineral.

O efeito quadrático da análise de regressão para a variável número de folhas, representado na Figura 5, mostra que houve diferença significativa $(\mathrm{p}<0,01)$, quanto à aplicação da manipueira via foliar na cultura do milho. $\mathrm{O}$ maior número médio de folhas registrada por planta, foi de 10,50 correspondente a aplicação de $75 \%$ de manipueira, o que corresponde a um aumento de $13,51 \%$ quando comparado com o tratamento que aplicou-se apenas água.

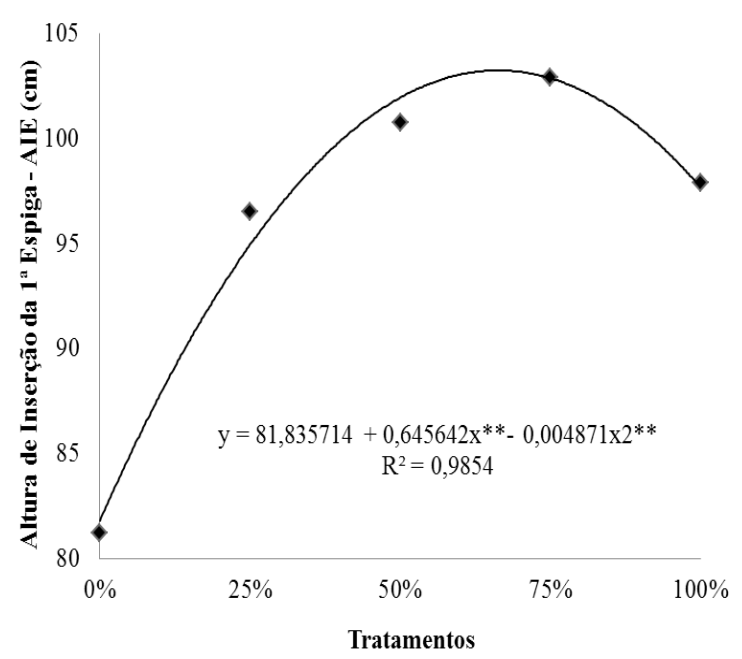

Figura 4. Regressão dos valores médios da altura de inserção da $1^{\text {a }}$ espigada (AIE, cm) do milho em função dos tratamentos.

Quadro 4. Resumo da análise de variância (Quadrado médio) das variáveis, altura de inserção $1^{\mathrm{a}}$ espiga (AIE), número de folhas (NF) e área foliar (AF), em função das concentrações $0 \%, 25 \%, 50 \%$, $75 \%$ e $100 \%$ de manipueira aplicada via foliar na cultura do milho

\begin{tabular}{lcccc} 
& & \multicolumn{3}{c}{ Quadrado Médio } \\
\cline { 3 - 5 } \multicolumn{1}{c}{ FV } & GL & AIE & NF & AF \\
\hline Regressão Linear & 1 & $628,05625^{* *}$ & $1,05625^{\text {ns }}$ & $646,25521^{\text {ns }}$ \\
Regressão Quadrática & 1 & $519,11162^{* *}$ & $1,96875^{* *}$ & $8.475,68435^{* *}$ \\
Desvio da Regressão & 2 & $11,00089^{\text {ns }}$ & $0,39375^{\text {ns }}$ & $1.183,31026^{\text {ns }}$ \\
Tratamento & 4 & $291,04375^{* *}$ & $0,85625^{* *}$ & $2.863,04593^{* *}$ \\
Bloco & 3 & $215,88333^{* *}$ & $1,94583^{* *}$ & $270.530,17347^{* *}$ \\
Resíduo & 12 & 4,97708 & 0,24792 & 553,52336 \\
CV\% & - & 2,32753 & 4,99160 & 4,01673 \\
\hline
\end{tabular}

**, * $\mathrm{e}^{\mathrm{ns}}$ - Significativo a 1 , a $5 \%$ de probabilidade e não significativo, respectivamente, (Teste $\mathrm{F}$ ).

Legenda: FV: Fonte de Variação; CV: Coeficiente de variação; GL: Grau de liberdade. 


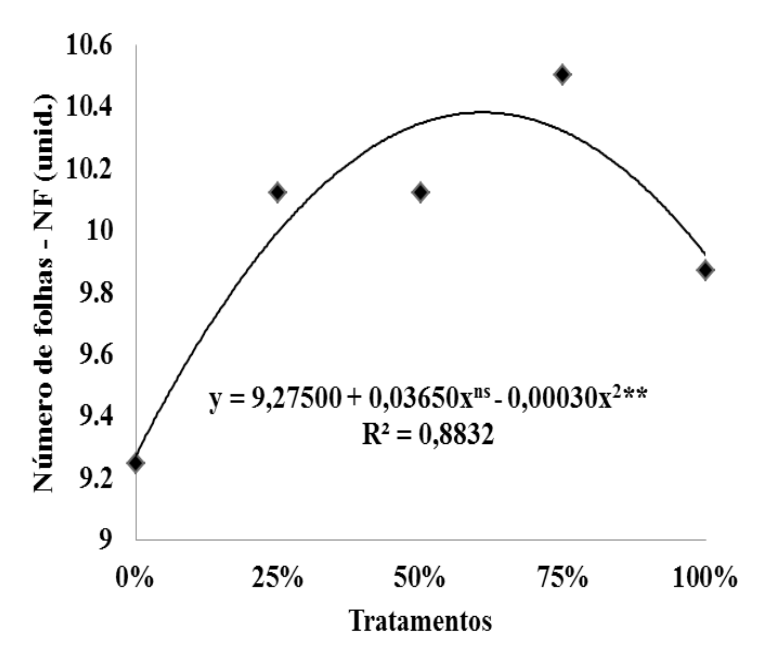

Figura 5. Regressão dos valores médios do número de folhas (NF, unid.) do milho em função dos tratamentos.

Ciancio (2010) estudou o efeito de doses crescentes de dejeto líquido de suíno e esterco de peru sem e com complementação de $\mathrm{N}$ mineral em cobertura, os resultados mostraram que doses de dejetos líquidos de animais complementados com a adubação mineral em cobertura favoreceram a produção de biomassa.

Cancellier et al. (2010), ao realizarem adubação orgânica com doses crescentes de esterco, uma adubação química como testemunha e como segundo fator duas doses de nitrogênio em cobertura, concluíram que a adubação química promove maior velocidade de crescimento, porém as plântulas neste tratamento tiveram maior dificuldade na emergência, os tratamentos com maiores doses de esterco bovino apresentaram emergência mais rápida, mesmo com adição de adubação orgânica, a aplicação de esterco curtido aplicado no sulco de plantio pode substituir a adubação química, sem comprometer o desempenho da cultura para a produção de biomassa.

Pinotti et al. (2009) estudaram a cultura do milho no município de Pompéia - SP, com base na variação das populações de plantas por hectare, com quatro diferentes populações de plantas por hectare, e na diversidade de fenótipos, com o número de quatro variedades, sendo avaliado o número de folhas por planta, na qual pode concluir que diferentes populações implicam em diferentes número de folhas por planta.
A análise de regressão polinomial para a variável, área foliar do milho apresentou efeito quadrático (Figura 6) com diferença significativa $(\mathrm{p}<0,01)$ entre tratamentos, sendo, 612,94 $\mathrm{cm}^{2}$ a máxima área foliar, correspondente ao tratamento com aplicação de $25 \%$ de manipueira. Esse valor corresponde a um aumento percentual de 12,32\%, em comparação a testemunha.

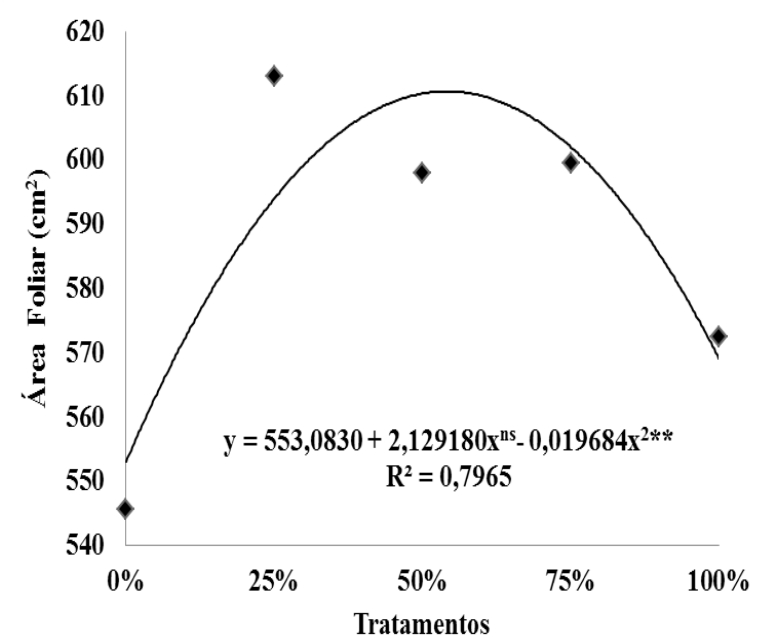

Figura 6. Regressão dos valores médios da área foliar $\left(\mathrm{AF}, \mathrm{cm}^{2}\right)$ do milho em função dos tratamentos.

Segundo Benicasa (1988), quanto maior a capacidade de absorção de luz de um vegetal, maior será a produtividade, pois, o seu desenvolvimento também será maior, logo a produtividade de uma cultura também está diretamente ligada a sua área foliar.

Santos et al. (2010) constataram que o cultivo orgânico do milho adubado com esterco, com o auxílio da adubação verde (gliricidia), foram benéficos para a produção de biomassa nesta gramínea, promoveu o acúmulo de nutrientes, porém, não apresentando esta um efeito residual significativo na cultura do milho. Cancellier et al. (2010) constataram que a dose de $40 \mathrm{t} \mathrm{ha}^{-1}$ de esterco propicia uma área foliar de $4909 \mathrm{~cm}^{2}$ por planta, sendo assim, 5,8\% superior ao tratamento testemunha. Também, a adubação nesta mesma dosagem de esterco, acrescida de $\mathrm{N}$ em cobertura, observa-se como significativamente superior, apresentando $5190 \mathrm{~cm}^{2}$ por planta.

Segundo Camargo \& Silva (1987), a adubação 
foliar com caldas muito concentrada pode causar injúria na planta. Essa afirmativa pode ser uma explicação para a inibição da variável diâmetro do caule, referente ao tratamento com aplicação de manipueira a $100 \%$ (manipueira pura), observado na Figura 3, e a seca nas folhas do milho na Figura 7.

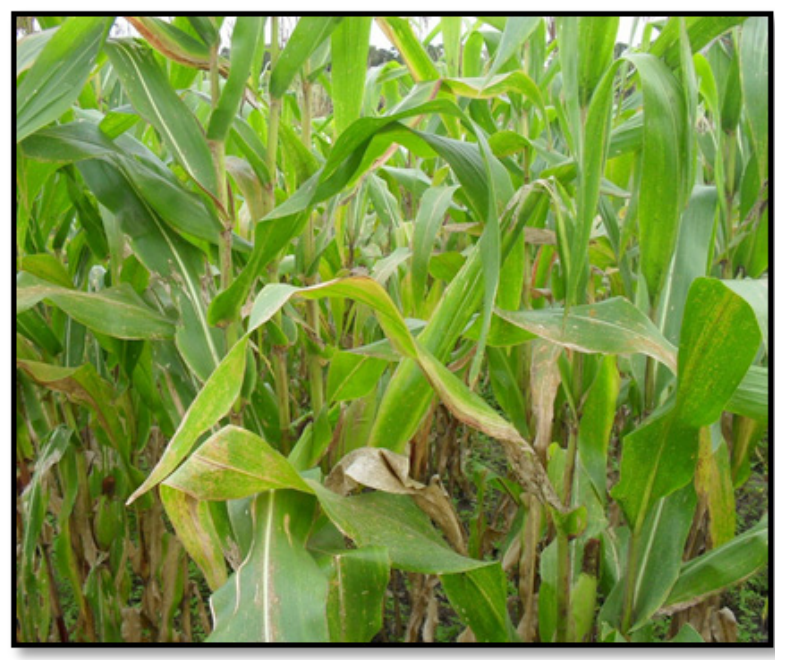

Figura 7. Injúrias em plantas de milho, em decorrência da aplicação de manipueira com concentração de $75 \%$ diluída em água e $100 \%$, via foliar. Lagoa Seca PB, 2010.

De acordo com o que está apresentado na Figura 7, a manipueira, quando aplicada em concentrações de 75 a 100\%, provocou severas injúrias nas folhas do milho, afetando seu tecido vegetal foliar. Uma provável explicação para o fenômeno pode ser devido à manipueira apresentar alta condutividade elétrica.

Já na Figura 8, representa-se porcentagem de folhas do milho, injuriadas em função dos tratamentos.

De acordo com o que esta apresentado na Figura 8, aplicações de manipueira nas concentrações de 75 e $100 \%$ causou injúria em 41,15 e $47,16 \%$, respectivamente, das folhas do milho. Essas concentrações elevadas de manipueira aplicada via foliar são prejudicias as plantas de milho, pois, as folhas que tiveram "injúrias", em quase todo o seu aparato fotossintético, provocaram intoxicação (seca) reduzindo sua área foliar e, consequentemente, prejudicando sua atividade fotossintética podendo gerar grandes perdas produtivas.

Segundo Camargo \& Silva (1987), para se evitar prejuízos com injúria, o ideal é fazer aplicações semanais com caldas menos concentradas. Nestas condições recomenda-se que a adubação foliar para a cultura do milho, utilizando-se manipueira, deve ser realizada 15 ou 20 dias após a germinação em concentrações inferiores a $50 \%$, objetivandose evitar injúria na planta, para garantir melhor produtividade.

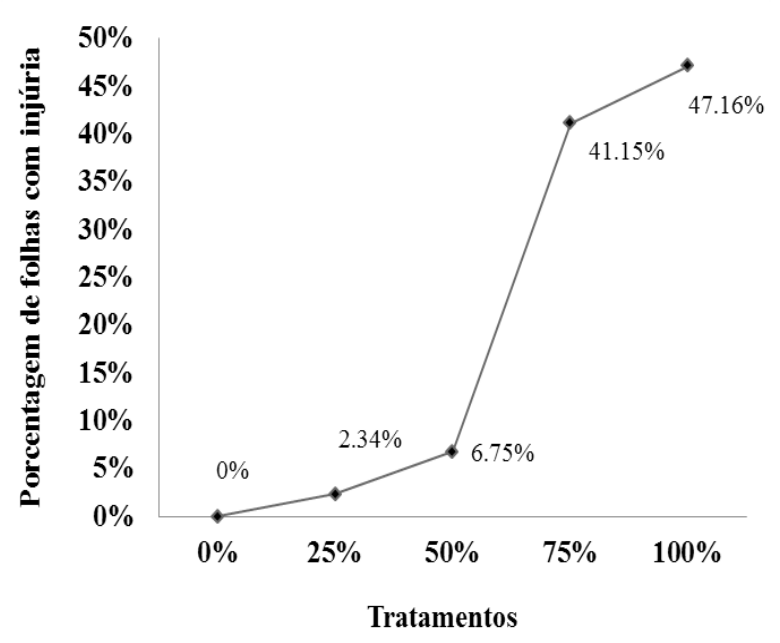

Figura 8. Porcentagem de folhas com injúria em função dos tratamentos.

\section{CONCLUSÕES}

Nas condições edafoclimáticas em que foi conduzido o experimento pode-se concluir que:

- A manipueira mostrou-se eficaz na adubação, via foliar, na cultura do milho;

- Todas as variáveis analisadas apresentaram valores superiores à testemunha absoluta;

- Quando se aplicou 75\% de manipueira, obtevese o máximo crescimento do caule, altura da planta, altura de inserção da $1^{\mathrm{a}}$ espiga e maior número de folhas; o maior diâmetro do caule foi obtido aplicando-se $50 \%$ de manipueira; a maior área foliar foi obtida quando se utilizou $25 \%$ de manipueira; e

- A aplicação de manipueira via foliar só é recomendável até a dosagem de $50 \%$, pois, acima desta dosagem, causam injúrias severas nas folhas do milho. 


\section{REFERÊNCIAS BIBLIOGRÁFICAS}

ALVES, W.W.A.; ALBUQUERQUE, J.H.; OLIVEIRA, F.A.; AZEVEDO, C.A.V.; DANTAS NETO, J. Água disponível no solo e adubação fosfatada: efeito sobre o crescimento e desenvolvimento do milho. Revista Verde de Agroecologia e Desenvolvimento Sustentável, Mossoró, RN, v.4, n.1, p.47- 53, 2009.

APHA. AWWA. WPCF. Standard Methods for the Examination of Water and Wastewater. 15.ed. Washington, DC. American Public Health Association. American Water Works Association, Water Pollution Control Federation, 1998.

ARAGÃO, M.L.; PONTE, J.J. O Uso da Manipueira - Extrato Líquido das Raizes de Mandioca - Como Adubo Foliar. Revista Ciência Agronômica, Fortaleza, CE, v.26, n.1, p.45 - 48, 1995.

BORSZOWSKEI, P.R.; MILLÉO, R.D.S.; AHRENS, D.C.; ROMANIW, J. Utilização de Manipueira como Adubo Natural Alternativo para a Cultura do Morangueiro (Fragaria x ananassa Duch.). VI Congresso Brasileiro de Agroecologia e II Congresso Latino Americano de Agroecologia. Anais... Curitiba/Paraná, 2009. CD - ROM.

BENICASA, M.M.P. Análise de crescimento de plantas (Noções básicas). São Paulo, SP. FCAVUNESP, 1988.

BORGHETTI, I.A. Avaliação do crescimento da microalga Chlorella minutíssima em meio de cultura com diferentes concentrações de manipueira. 2009. 103f. Dissertação (Mestrado em Processos Biotecnológicos) - Universidade Federal do Paraná. Curitiba, 2009.

BRITO, K.S.; LYRA, G.B.; LYRA, G.B.; SOUZA, J.L. TEODORO, I.; SILVA, M.; ROCHA, A.E. Q.; SILVA, S. Produtividade e índice de área foliar do milho em função da adubação nitrogenada. In: XXVIII CONGRESSO NACIONAL DE MILHO E SORGO, Goiânia, 2010. Anais... Goiânia: Associação Brasileira de Milho e Sorgo, 2010. CD - ROM.
BRASIL. Instituto Brasileiro de Geografia e Estatística - IBGE. Estatística da produção agrícola. Janeiro de 2011. Disponível em: $<$ http:// www.ibge.gov.br/home/estatistica/indicadores/ agropecuaria/lspa/default.shtm $>$. Acesso em 22 de fevereiro de 2011.

CAMARGO, N. P.; SILVA, O. Manual de adubação foliar. Editoras, La Libreria e Herba Ltda. São Paulo, SP, 1987.

CANCELLIER, L.L.; AFFÉRRI, F.S.; ADORIAN, G.C.; RODRIGUES, H.V. Influência da adubação orgânica na linha de semeadura na emergência e produção forrageira de milho. Revista Verde de Agroecologia e Desenvolvimento Sustentável, Mossoró, RN, v. 5, n. 5, p. 25 - 32 (Número Especial) dezembro de 2010.

CARDOSO, É. Uso de manipueira como biofertilizante no cultivo do milho: Avaliação do efeito no solo, nas águas subterrâneas e na produtividade do milho. 2005. 67f. Dissertação (Mestrado em Ciências Anbientais) - Universidade do Extremo Sul Catarinense. Criciúma, 2005.

CASTRO,A.M.C.; PREZOTTO,A.L. Desempenho agronômico do milho em sistema de adubação verde. Revista Agrarian, Dourados, MS, v. 1, n. 2 , p. 35 - 44, out. /dez. 2008.

CEREDA, M.P. Caracterização dos Subprodutos da Industrialização da Mandioca. In: CEREDA, M.P (coord): Manejo, Uso e Tratamento de Subprodutos da Industrialização da Mandioca. Fundação Cargill, São Paulo, SP, v.4, p.13 - 37, 2001.

CIANCIO, N.H.R. Produção de grãos, matéria seca e acúmulo de nutrientes em culturas submetidas à adubação orgânica e mineral. 2010. 85f. Dissertação (Mestrado em Ciências do Solo) - Universidade Federal de Santa Maria. Santa Maria, 2010.

COLLARD, F.H.;ALMEIDA, A.; COSTA, M.C.R.; ROCHA, M.C. Efeito do Uso de Biofertilizante Agrobio na Cultura do Maracujazeiro Amarelo (Passiflora edulis f. flavicarpa Deg). Revista 
Biociência,Taubaté, SP, v.7, n.1, p.15 - 21, jan. jun. 2001 .

EMBRAPA - Empresa Brasileira de Pesquisa Agropecuária. Centro Nacional de Pesquisa de Solos. Sistema Brasileiro de Classificação de Solos. Rio de Janeiro: Embrapa Solos, 1999.

FIORETTO, R.A. Uso Direto da Manipueira em Fertirrigação. In: CEREDA, M. P (Coord.): Manejo, Uso e Tratamento de Subprodutos da Industrialização da Mandioca. Fundação Cargill, São Paulo, SP, v.4, p.67 - 79, 2001.

FRANCIS, C.A.; RUTGER, J.N.; PALMER, A.F.E. A rapid method for plant leaf area estimation in maize (Zea mays L.). Crop Science, Ontario, v.9, p.537-539, 1969.

MELO, R.F.; FERREIRA, P.A.; MATOS, A.T.; RUIZ, H.A.; OLIVEIRA, L.B. Deslocamento miscível de cátions básicos provenientes da água residuária de mandioca em colunas de solo. Revista Brasileira de Engenharia Agrícola e Ambiental, Campina Grande, PB, v.10, n.2, p.456 - 465, 2006.

OLIVEIRA, F.A.; CAVALCANTE, L.F.; SILVA, I.F.; PEREIRA, W.E.; OLIVEIRA, J.C.; FILHO, J. F.C. Crescimento do milho adubado com nitrogênio e fósforo em um latossolo amarelo. Revista Brasileira de Ciências Agrárias. Recife, PE, v.4, n.3, p.238 - 244, jul. - set., 2009.

PANTAROTO, S.; CEREDA, M.P. Linamarina e sua decomposição no ambiente. In: CEREDA, M.P (coord.): Manejo, uso e tratamento de subprodutos da industrialização da mandioca. Fundação Cargill, São Paulo, SP, v.4, p.38 - 47, 2001.

PINOTTI, E.B.; ALMEIDA, D.; ARAÚJO, H.M.; BARBOSA, R.Z.; PETÍLIO, A.A. Características vegetativas de três cultivares de milho (Zea mays L.) sob quatro populações de plantas em espaçamento reduzido. Revista Científica de Agronomia,
Garça, SP, Número 15, Junho de 2009.

SANTOS, A.F.; MENEZES, R.S.C.; FRAGA, V.S.; PÉREZ-MARIN, A.M. Efeito residual da adubação orgânica sobre a produtividade de milho em sistema agroflorestal. Revista Brasileira Engenharia Agrícola e Ambiental, Campina Grande, PB, v.14, n.12, p.1267-1272, 2010.

SANTOS, P.A.; SILVA, A.F.; CARVALHO, M.A.C.; CAIONE, G. Adubos verdes e adubação nitrogenada em cobertura no cultivo do milho. Revista Brasileira de Milho e Sorgo, Sete Lagoas, MG, v.9, n.2, p.123 -134, 2010.

SARAIVA, F.Z.; SAMPAIO, S.C.; SILVESTRE, M.G.; QUEIROZ, M. M.F.; NÓBREGA, L.H.P.; GOMES, B.M. Uso de manipueira no desenvolvimento vegetativo do milho em ambiente protegido. Revista Brasileira de Engenharia Agrícola e Ambiental, Campina Grande, PB, v.11, n.1, p.30-36, 2007.

SIQUEIRA, B.C.; FERNANDES, L.G.; CAMPOS, K.A.; ESTANISLAU,A.C.; PEDINI, S.; MORAIS, A.R. Ação dos fertilizantes bacsol e orgasol na altura de inserção da espiga e coloração dos grãos na cultura do milho orgânico. In: II SEMANA DE CIÊNCIA E TECNOLOGIA DO IFMG CAMPUS BAMBUÍ. II Jornada Científica, Bambuí, 2009. Disponível em: <http://www. google.com/search?hl=pt-BR\&client $=$ ubuntu\& $\mathrm{hs}=\mathrm{uiu} \& \mathrm{channel}=\mathrm{fs} \& \mathrm{biw}=1440 \& \mathrm{bih}=675 \& \mathrm{q}=$ Aduba $\%$ C3\%A7\%C3\%A3o+organica + do + milh $\mathrm{o}+$ influencia + na + altura + da + espiga\&oq $=$ Aduba $\% \mathrm{C} 3 \% \mathrm{~A} 7 \% \mathrm{C} 3 \% \mathrm{~A} 3 \mathrm{o}+$ organica + do + milho+influ encia + na + altura + da + espiga $\& a q=f \& a q i=\& a q l=\&$ gs_sm $=$ e\&gs_upl $=13026130365101331321013010101$ 340163812-1.1>. Acesso em 03 de Junho de 2011.

TAKAHASHI, M. Aproveitamento da manipueira e de resíduos do processamento da mandioca. Informe Agropecuário, Belo Horizonte, ano 13, n.145, p.83 -87 , jan, 1987. 